\title{
Presentation and outcomes in surgically and conservatively managed pediatric Rathke cleft cysts
}

\author{
Matthew J. Shepard, MD, ${ }^{1}$ Mohamed A. Elzoghby, MD, ${ }^{1,4}$ Erin N. Kiehna, MD, ${ }^{3}$ \\ Spencer C. Payne, MD, ${ }^{2}$ and John A. Jane Jr., MD ${ }^{1}$
}

Departments of ${ }^{1}$ Neurosurgery and ${ }^{2}$ Otolaryngology, University of Virginia Health System, Charlottesville, Virginia; ${ }^{3}$ Department of Neurosurgery, Children Hospital, Los Angeles, California; and ${ }^{4}$ Department of Neurosurgery, Ain Shams University, Cairo, Egypt

\begin{abstract}
OBJECTIVE Rathke cleft cysts (RCCs) are sellar lesions that are commonly encountered in adults but infrequently diagnosed in the pediatric population. As a result, the optimal management of pediatric RCCs remains a subject of controversy. Only 2 prior surgical series have been published on pediatric RCCs and no study has compared the presentation and outcomes of surgically versus conservatively managed cases. The authors therefore performed a comparative analysis of pediatric cases of RCC in which patients were treated with surgery or managed in a conservative manner.

METHODS All cases involving pediatric patients diagnosed with an RCC at the University of Virginia between 2000 and 2016 were included in this study. Patient medical records, operative notes, and neuroimaging findings were reviewed. Patients who developed visual field deficits, radiographic evidence of chiasmal compression, or medically refractory headaches were considered candidates for surgical intervention. All patients who were selected for surgery underwent an endoscopic endonasal approach with cyst fenestration.
\end{abstract}

RESULTS A total of 24 pediatric patients were diagnosed with an RCC over a 16-year period. Seven patients ultimately underwent transsphenoidal cyst fenestration, and 17 were managed conservatively. The patients' age at diagnosis, cyst size, and pituitary function at the time of RCC diagnosis were similar in the conservatively and surgically managed cohorts. At diagnosis, 19 of 24 patients endorsed headaches that led to neuroimaging. All patients in the surgical cohort endorsed severe headaches at diagnosis compared with $71 \%$ in the conservative group. For the 7 patients treated with surgery, complete cyst evacuation was achieved in $86 \%$ of cases. Transient postoperative endocrinopathy occurred in 4 $(57 \%)$ of 7 surgically treated individuals and resolved in all cases. In the conservative cohort, 1 patient developed a delayed pituitary-related endocrinopathy. Headache resolution occurred in $5(71 \%)$ of the 7 patients who underwent surgery and $7(58 \%)$ of the 12 who were treated without surgery. Cyst recurrence was documented in 1 individual in the surgical cohort who underwent a subtotal cyst fenestration that ultimately required re-intervention. In the conservative cohort, spontaneous cyst shrinkage occurred in $35 \%$ of patients with a median time to regression of 23.5 months.

CONCLUSIONS Pediatric RCCs are benign sellar lesions that often present with headaches. While cyst fenestration mitigates headaches in most patients, the majority of conservatively managed pediatric patients with RCCs will have spontaneous headache resolution. Furthermore, spontaneous RCC regression occurs in a substantial number of individuals. Thus, in the absence of optic compression, visual field deficit, or diagnostic uncertainty, many pediatric cases of RCC can be managed conservatively.

https://thejns.org/doi/abs/10.3171/2017.9.PEDS17400

KEY WORDS endoscopic; transsphenoidal; pediatric; Rathke cleft cyst; pituitary surgery

$\mathrm{R}$ ATHKE cleft cysts (RCCs) are benign, fluid-filled remnants of Rathke's pouch, situated between the adeno- and neurohypophysis. $7,9,27$ RCCs are commonly encountered in adults and have been described in up to one-third of cases at autopsy. ${ }^{9,21,24}$ Although benign and often asymptomatic, RCCs can expand and exert local mass effect, leading to the development of headaches, chiasmal compression, or hormonal dysfunction. ${ }^{1,9}$ Despite their prevalence, RCCs are often incidentally diagnosed and account for less than $10 \%$ of symptomatic sellar lesions in adult surgical series. ${ }^{1,21}$

In contrast to the high prevalence of RCCs in the adult population, RCCs are seldom diagnosed in children and adolescents. While the prevalence of pediatric RCCs is not defined, an evaluation of 341 neuroimaging studies performed in patients under the age of 15 showed that $1.2 \%$

ABBREVIATIONS DI = diabetes insipidus; $\mathrm{GH}=$ growth hormone; HPA = hypothalamic-pituitary axis; RCC = Rathke cleft cyst.

SUBMITTED July 18, 2017. ACCEPTED September 5, 2017.

INCLUDE WHEN CITING Published online December 22, 2017; DOI: 10.3171/2017.9.PEDS17400. 
had asymptomatic cystic lesions of the pituitary gland. ${ }^{23}$ Furthermore, it has been suggested that the incidence of these benign lesions is rising due to the increased utilization of advanced imaging modalities in pediatric patients. ${ }^{19}$

On MRI, RCCs are often hyperintense on T2-weighted images with either a hyper- or a hypointense appearance on T1-weighted images depending upon cyst content. ${ }^{9} \mathrm{Un}$ like craniopharyngiomas, which are much more frequently encountered in the pediatric population, RCCs typically lack contrast enhancement and do not have evidence of calcification..$^{10,20}$ As for adults, headaches, hormonal disturbance, and visual loss have been commonly reported for pediatric patients with RCCs..$^{10,13,28}$

While the natural history and surgical outcomes of RCCs in adults have been described in larger series, the natural history and optimal management of pediatric RCCs is less clear owing to the rarity with which these lesions have been reported. ${ }^{1,4,9,10,13,28}$ Indeed, to date, a total of less than 200 cases of RCC have been described in the literature, and only 60 surgical cases have been described. . $, 5,6,8,10-13,15-19,22,23,25,26,28$ Only 2 prior dedicated surgical series on pediatric RCC have been published, and no study has compared the presentation and outcomes of surgically versus conservatively managed pediatric patients with RCCs. ${ }^{13,28}$

Thus, in this investigation we sought to compare the outcomes of pediatric RCCs managed either surgically or conservatively at a single institution. The nonsurgical cases discussed herein were also included in the 2015 study by Culver et al. ${ }^{4}$

\section{Methods}

\section{Study Design}

An institutional review board-approved retrospective review was performed for all cases involving patients who were diagnosed with an RCC at the University of Virginia between 2000 and 2016. In cases where pathological specimens were available, the diagnosis of an RCC was confirmed by a neuropathologist. In instances where tissue was not available for histological review, the diagnosis was determined by MRI. All available imaging was reviewed by a neurosurgeon and neuroradiologist. Patients were included for this study if they were 18 years of age or younger at the time of RCC diagnosis.

\section{Surgical Intervention}

Patients who developed visual field deficits, radiographic evidence of chiasmal compression, or medically refractory headaches were considered candidates for surgical intervention. All patients who received surgery underwent an endoscopic transsphenoidal approach to the sella that has been described previously. ${ }^{14}$ In each case, cyst fenestration was performed with concurrent cyst wall biopsy as advocated by Aho et al. ${ }^{1}$

\section{Clinical and Radiographic Follow-Up}

Patients' cases were included for analysis if they had at least 6 months of documented neurosurgical follow-up and at least 1 repeat MRI study of the brain. All patients underwent independent endocrinological evaluation for assessment of the hypothalamic-pituitary axis (HPA) at the time of diagnosis. In instances where visual field impairment was suspected, patients were evaluated by a neuro-ophthalmologist for formal visual field analysis. Cyst progression was defined as an increase in the maximum cyst diameter of $20 \%$. Cyst shrinkage was defined as a decrease in the maximum cyst diameter of at least $20 \%$. Patients were followed annually with repeat MRI and endocrinological evaluations. The degree of postoperative fenestration was determined on the basis of 3-month postoperative MRI. Cyst recurrence was defined as a progressively enlarging sellar/suprasellar cyst.

\section{Data Collection}

Patient charts were retrospectively reviewed for demographic information and symptomology. The presence and degree of headaches and visual field deficits were particularly noted. Laboratory data were reviewed for baseline and final concentrations of prolactin, cortisol, growth hormone $(\mathrm{GH})$, insulin-like growth factor-1, thyroid-stimulating hormone, luteinizing hormone, and follicle-stimulating hormone.

\section{Statistical Analysis}

Descriptive statistical analysis was performed. The median and range were determined for continuous variables, and the frequency and percentages were calculated for categorical data. The Student t-test was used for continuous variables, and chi-square analysis was performed for categorical data; $p<0.05$ was considered to indicate statistical significance. All analysis was performed using Prism statistical software (version 7.0b).

\section{Results \\ Presentation}

A total of 24 pediatric patients (11 male and 13 female) were diagnosed with RCCs between 2000 and 2016 at the University of Virginia. Seven patients ultimately underwent transsphenoidal fenestration of their RCC, while 17 were managed conservatively. Table 1 summarizes the differences in patient age, duration of follow-up, cyst characteristics, and symptomology between the conservatively and surgically managed cases. The patients' median age at diagnosis of RCC was 13 years for both surgically and conservatively managed cases (overall range 1-18 years). The median cyst diameter tended to be larger in surgically treated cases $(1.2 \mathrm{~cm})$ than for those managed conservatively $(0.9 \mathrm{~cm})$, but this difference was not statistically significant. Patients whose cases were managed in a conservative fashion had a median duration of clinical followup of 50 months (range 8-180 months) with a median radiographic follow-up of 39 months (range 11-147 months). Patients who underwent surgery tended to be followed longer, with a median duration of clinical and radiographic follow-up of 91 months (range 24-109 months) and 90 months (range 30-109 months), respectively. The median duration of postoperative follow-up was 87 months (range 5-109 months).

At the time of diagnosis, 19 (79\%) of 24 patients en- 
TABLE 1. Comparison of baseline characteristics of conservatively and surgically managed RCCs

\begin{tabular}{|c|c|c|c|c|}
\hline \multirow[b]{2}{*}{ Characteristic } & \multirow{2}{*}{$\begin{array}{c}\text { All RCC } \\
\text { Cases }\end{array}$} & \multicolumn{2}{|c|}{ Management } & \multirow{2}{*}{$\begin{array}{c}p \\
\text { Value }\end{array}$} \\
\hline & & Conservative & Surgical & \\
\hline \multicolumn{5}{|l|}{ Age (yrs) } \\
\hline Median & 13 & 13 & 13 & 0.2 \\
\hline Range & $1-18$ & $1-18$ & $8-18$ & \\
\hline \multicolumn{5}{|l|}{ Clinical FU (mos) } \\
\hline Median & 58 & 50 & 91 & 0.4 \\
\hline Range & $8-180$ & $8-180$ & 24-109 & \\
\hline \multicolumn{5}{|l|}{$\begin{array}{l}\text { Radiographic FU } \\
\text { (mos) }\end{array}$} \\
\hline Median & 56 & 39 & 90 & 0.2 \\
\hline Range & $5-147$ & $11-147$ & $30-109$ & \\
\hline \multicolumn{5}{|l|}{ Symptom } \\
\hline $\mathrm{HA}$ & 19/24 (79\%) & $12 / 17(71 \%)$ & $7 / 7(100 \%)$ & 0.1 \\
\hline $\begin{array}{c}\text { Precocious } \\
\text { puberty }\end{array}$ & $1 / 24(4 \%)$ & $1 / 17(6 \%)$ & $0 / 7(0 \%)$ & 0.5 \\
\hline Growth delay & $1 / 24(4 \%)$ & $1 / 17(6 \%)$ & $0 / 7(0 \%)$ & 0.5 \\
\hline Vision loss & $1 / 24(4 \%)$ & $0 / 17(0 \%)$ & $1 / 7(0 \%)$ & 0.1 \\
\hline Incidental & $3 / 24(13 \%)$ & $3 / 17(18 \%)$ & $0 / 7(0 \%)$ & 0.2 \\
\hline \multicolumn{5}{|l|}{ Endocrine evaluation } \\
\hline Hypopituitarism & $2 / 24(8 \%)$ & $1 / 17(5.8 \%)$ & $1 / 7(14 \%)$ & 0.3 \\
\hline Elevated PRL & $1 / 24(4 \%)$ & $1 / 17(6 \%)$ & $0 / 7(0 \%)$ & 0.5 \\
\hline DI & $1 / 24(4 \%)$ & $1 / 17(6 \%)$ & $0 / 7(0 \%)$ & 0.5 \\
\hline \multicolumn{5}{|l|}{ Cyst diameter (cm) } \\
\hline Median & 0.9 & 0.9 & 1.2 & 0.3 \\
\hline Range & $0.3-1.9$ & $0.3-1.9$ & $0.5-1.7$ & \\
\hline Cyst growth & $6 / 21(29 \%)$ & $5 / 17(29 \%)$ & $1 / 4(25 \%)$ & 0.6 \\
\hline Cyst shrinkage & $6 / 21(29 \%)$ & $6 / 17(35 \%)$ & $0 / 4(0 \%)$ & 0.2 \\
\hline $\mathrm{HA}$ at last FU & $7 / 24(29 \%)$ & $5 / 17(29 \%)$ & $2 / 7(29 \%)$ & 1.0 \\
\hline
\end{tabular}

$\mathrm{FU}=$ follow-up; $\mathrm{HA}=$ headache; $\mathrm{PRL}=$ prolactin.

dorsed headaches that led to neuroimaging. All of the surgically treated patients endorsed severe headaches compared with $71 \%$ of the conservatively treated patients. The diagnosis of RCC in the remaining 5 patients without headache was made during the evaluation of short stature, idiopathic hypothyroidism, precocious puberty, failure to thrive, or seizures. Two patients endorsed reduced peripheral vision at the time of diagnosis, and one of these patients was found to harbor a dense bitemporal hemianopsia on formal neuro-ophthalmological evaluation. Both underwent surgery. No patient in the conservatively treated group presented with visual field deficits.

The baseline characteristics of the surgical cohort are summarized in Table 2. Surgical indications included medically refractory headaches (in cases $2,3,4,5$, and 7), radiographic evidence of chiasmal compression (in case 1), visual field deficit (in case 6), and cyst enlargement (in case 3). Representative MR images from cases managed conservatively and with surgery are shown in Fig. 1.

\section{Presenting Endocrinological Assessment}

At the time of RCC diagnosis, 6 patients (25\%) had laboratory evidence of an endocrinopathy. Endocrinopathy was attributable to pituitary dysfunction in $3(50 \%)$ of these 6 cases. These included 2 cases of hypogonadotropic hypogonadism (34\%) and a single case of diabetes insipidus (DI; 17\%). The non-pituitary-related causes of endocrine dysfunction included precocious puberty (17\%), primary hypothyroidism (17\%), and a mildly elevated prolactin level in a patient with a seizure disorder (17\%). Five (83\%) of the 6 patients who presented with endocrinopathy $(83 \%)$ were treated in a conservative fashion. The 1 patient who underwent cyst fenestration with an endocrinopathy had a low testosterone level (186 ng/dl).

\section{Outcomes in Conservatively and Surgically Managed Cases}

At the last follow-up, 29\% of the patients in each group (conservatively and surgically managed cases) reported persistent headaches. While $5(71 \%)$ of 7 of the surgically treated patients experienced headache resolution, headaches resolved without intervention in 7 (58\%) of the 12 conservatively managed patients who originally presented with headache. At last follow-up, of the 7 patients who noted headache improvement, no patient required ongoing medical therapy for headaches. Of the 5 conservatively treated patients who still endorsed headaches at last follow-up, only 2 patients (40\%) required ongoing medical therapy. There was no statistically significant difference in

TABLE 2. Characteristics of pediatric patients undergoing transsphenoidal fenestration of RCCs

\begin{tabular}{|c|c|c|c|c|c|c|c|c|c|}
\hline $\begin{array}{l}\text { Case } \\
\text { No. }\end{array}$ & $\begin{array}{l}\text { Age (yrs), } \\
\text { Sex }\end{array}$ & $\begin{array}{l}\text { Cyst Diam } \\
(\mathrm{cm})\end{array}$ & Presentation & Endocrinopathy & Indication & Complications & $\begin{array}{c}\text { HA } \\
\text { Resolution }\end{array}$ & $\begin{array}{c}\text { Degree of } \\
\text { Fenestration }\end{array}$ & Recurrence \\
\hline 1 & $8, M$ & 1.4 & $\mathrm{HA}$ & - & $\begin{array}{l}\mathrm{HA} \text {, chiasmal com- } \\
\text { pression }\end{array}$ & Transient DI & Yes & GT & No \\
\hline 2 & $13, \mathrm{M}$ & 1.4 & $\mathrm{HA}$ & - & $\mathrm{HA}$ & Transient DI & Yes & GT & No \\
\hline 3 & $12, \mathrm{~F}$ & 1.1 & $\mathrm{HA}$ & - & $\mathrm{HA}$, cyst progression & None & Yes & GT & No \\
\hline 4 & $13, F$ & 0.5 & $\mathrm{HA}$, weight gain & - & $\mathrm{HA}$ & None & No & GT & No \\
\hline 5 & $16, F$ & 0.9 & $\mathrm{HA}$ & - & $\mathrm{HA}$ & Transient DI, Al & Yes & GT & No \\
\hline 6 & $17, \mathrm{~F}$ & 1.7 & $\mathrm{HA}+\mathrm{VFD}$ & - & VFD, HA & Postop, epistaxis & No & ST & Yes \\
\hline 7 & $18, M$ & 1.2 & $\mathrm{HA}$ & Low test & $\mathrm{HA}$ & None & Yes & GT & No \\
\hline
\end{tabular}

$\mathrm{Al}=$ adrenal insufficiency; diam = diameter; $\mathrm{GT}$ = gross-total fenestration; $\mathrm{ST}$ = subtotal fenestration; test = testosterone; VFD = visual field deficit. 

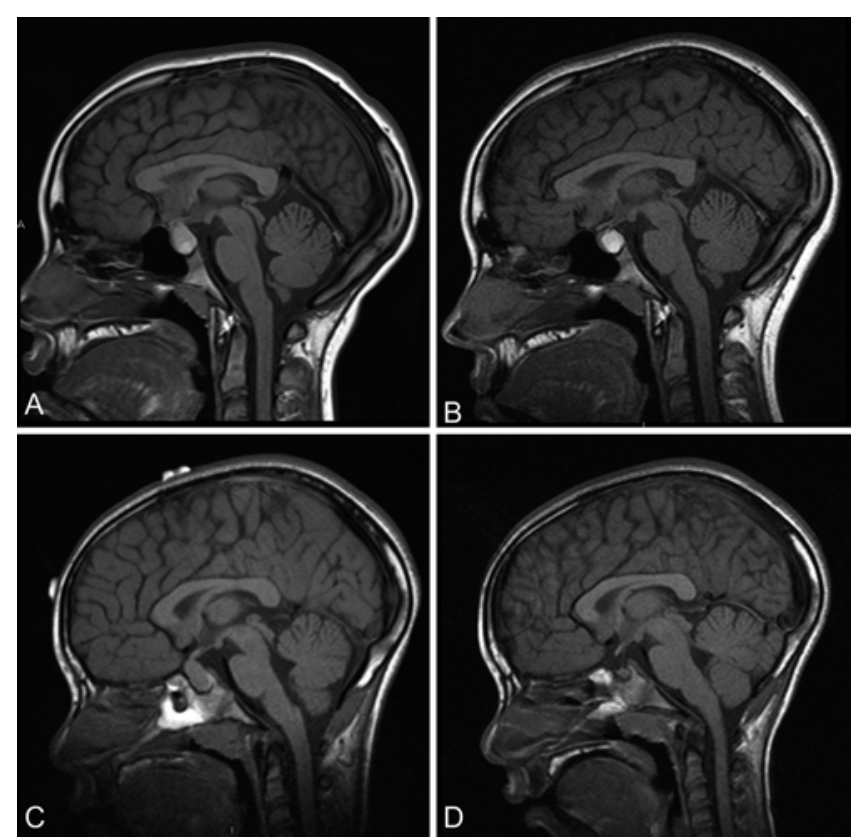

FIG. 1. Sagittal T1-weighted MR images obtained in a conservatively managed case ( $A$ and $B$ ) and a surgically managed case ( $C$ and D). A: MR image obtained in a 14-year-old girl who presented with progressive headaches and was found to harbor a $1.6 \times 1.1-\mathrm{cm}$ RCC. Her headaches were adequately controlled, and in the absence of visual symptoms her case was managed conservatively. B: Image from repeat MRI study performed 14 months later showing spontaneous cyst shrinkage $(1.1 \times 1.0 \mathrm{~cm})$. C: MR image obtained in an 8-year-old boy who presented with acute onset of severe, medically refractory headaches, revealing a $1.4 \times 0.8-\mathrm{cm}$ RCC. The patient underwent successful endoscopic cyst fenestration, and his headaches improved following surgery. D: MR image obtained 1 year after surgery showing no evidence of cyst recurrence.

headache improvement in the surgically and conservatively managed cases. No patient in the conservatively managed cohort developed delayed visual field deficits. The patient with documented visual field loss prior to surgery had normalization of her visual fields by the last follow-up.

Surgery provided complete evacuation of cyst contents in $6(86 \%)$ of 7 patients as gauged on 3-month postoperative MRI. The individual who had persistent evidence of $\mathrm{RCC}$ on postoperative imaging had recurrence of her RCC 6 months following surgery, requiring repeat fenestration, which was complicated by epistaxis requiring intervention. The patient's imaging findings have been subsequently stable for 65 months.

In the surgical group, the median time from RCC diagnosis to surgery was 5 months (range $<1-34$ months). In this group, repeat MRI studies were obtained in 4 cases prior to surgery, with cyst progression noted in 1 of these 4 cases. Cyst progression occurred in 6 patients (25\%) in this study-in $5(29 \%)$ of the 17 patients in the conservative cohort and in $1(14 \%)$ of the 7 patients in the surgical cohort. The median time to cyst progression in these 5 cases was 72 months (range 6-110 months), and in 1 of the cases, progression occurred after the cyst initially regressed on imaging. The progression of the RCC in these individuals was not associated with a change in symptoms, visual phenomena, or development of a new endocrinopathy.
TABLE 3. Comparison of characteristics of RCC with or without spontaneous shrinkage

\begin{tabular}{lccc}
\hline \multicolumn{1}{c}{ Characteristic } & Cyst Shrinkage & No Regression & $\mathrm{p} \mathrm{Value}$ \\
\hline Median age at Dx (yrs) & 8.5 & 13 & 0.1 \\
\hline Mean cyst diam at Dx (cm) & 1.1 & 0.8 & 0.1 \\
\hline Female sex & $3 / 6(50 \%)$ & $10 / 15(67 \%)$ & 0.5 \\
\hline HA at Dx & $3 / 6(50 \%)$ & $13 / 15(87 \%)$ & 0.1 \\
\hline HA at last FU & $2 / 6(33 \%)$ & $5 / 15(33 \%)$ & 1.0 \\
\hline Cyst progression & $3 / 6(50 \%)$ & $3 / 15(20 \%)$ & 0.2 \\
\hline Endocrinopathy & $3 / 6(50 \%)$ & $2 / 15(13 \%)$ & 0.1 \\
\hline
\end{tabular}

$\mathrm{Dx}=$ diagnosis.

Spontaneous cyst shrinkage occurred in 6 patients $(35 \%)$ in the conservatively managed cohort, with a median time to regression of 23.5 months (range 12-117 months). Spontaneous cyst shrinkage occurred in 2 of these 6 patients after their cyst had demonstrated progression. No patient had evidence of cyst regression in the surgically managed cohort. Patients who demonstrated spontaneous cyst regression tended to be younger at the time of RCC diagnosis (median age 8.5 vs 13 years) and have larger cysts at diagnosis (1.1 vs $0.8 \mathrm{~cm}$ ), but these differences were not statistically significant (Table 3). Patients with cyst shrinkage were more likely to present with an underlying endocrinopathy but less likely to present with headaches, although the sample size was small, and these results did not achieve statistical significance (Table 3). The likelihood of headaches at last follow-up was not affected by cyst regression status.

Of the 12 individuals in the conservatively managed cohort who had normal HPA at RCC diagnosis, 2 (17\%) developed a subsequent endocrinopathy during followup. One patient developed Hashimoto's thyroiditis and ultimately was treated for primary hypothyroidism, and the other patient, a 10-year-old boy, developed symptomatic GH deficiency 12 months after RCC diagnosis that required treatment with $\mathrm{GH}$ replacement therapy. In the operative cohort, the 1 individual who presented with low testosterone had normalization of his testosterone level following surgery. Transient postoperative endocrinopathy occurred in $4(57 \%)$ of the 7 surgically treated patients. This included transient postoperative DI in 3 patients $(43 \%)$ and postoperative adrenal insufficiency, requiring a short course of hydrocortisone, in the fourth patient. At last follow-up, however, no surgical patient required hormonal replacement therapy or was undergoing treatment for DI.

\section{Discussion}

Rathke's cleft cysts are benign, cystic lesions of the sella that are rarely encountered by the pediatric neurosurgeon. ${ }^{28}$ Indeed, much of the inquiry into the natural history of RCCs has been described in the adult literature.1,4 Therefore, we analyzed one of the largest series of pediatric RCCs and uniquely compared the presentation and clinical, endocrinological, and radiological outcomes in both surgically and conservatively managed cases. 
TABLE 4. Previously reported cases of pediatric RCCs

\begin{tabular}{|c|c|c|c|c|c|c|c|c|c|c|c|c|c|}
\hline \multirow[b]{2}{*}{ Authors \& Year } & \multirow[b]{2}{*}{$\begin{array}{c}\text { No. of } \\
\text { Pts }\end{array}$} & \multirow[b]{2}{*}{$\begin{array}{c}\text { Median } \\
\text { Age (yrs) }\end{array}$} & \multirow[b]{2}{*}{$\begin{array}{l}\text { Cyst Diam } \\
\text { (cm) }\end{array}$} & \multirow[b]{2}{*}{$\begin{array}{l}\text { Op, n } \\
(\%)\end{array}$} & \multirow[b]{2}{*}{$\begin{array}{c}\text { FU } \\
\text { (mos) }\end{array}$} & \multicolumn{3}{|c|}{ Presentation } & \multicolumn{5}{|c|}{ Surgical Outcomes } \\
\hline & & & & & & $\begin{array}{l}\text { VFD } \\
(\%)\end{array}$ & $\begin{array}{c}\text { Hypopit } \\
(\%)\end{array}$ & $\begin{array}{c}\text { Incid } \\
(\%)\end{array}$ & $\begin{array}{c}\text { Pit Impr } \\
(\%)\end{array}$ & $\begin{array}{c}\text { Pit Worse } \\
(\%)\end{array}$ & $\begin{array}{l}\text { DI } \\
(\%)\end{array}$ & $\begin{array}{l}\text { GT } \\
(\%)\end{array}$ & $\begin{array}{c}\text { Recur } \\
(\%)\end{array}$ \\
\hline Hayashi et al., 2016 & 11 & 12.2 & 1.9 & $8(72)$ & 85 & 18 & 45 & 0 & 40 & 0 & 25 & - & 25 \\
\hline Daubenbüchel et al., 2015 & 14 & 11.3 & 1.8 & - & 50 & - & - & - & - & - & - & - & - \\
\hline Oh et al., 2014 & 34 & 9.7 & 0.6 & $0(0)$ & - & 0 & 76 & 9 & - & - & - & - & - \\
\hline Jahangiri et al., 2011 & 14 & 16 & 1.2 & $14(100)$ & 38 & 7 & 45 & 14 & 43 & - & 21 & 86 & 14 \\
\hline Lim \& Yang, 2010 & 44 & 10.1 & - & $15(34)$ & 16 & 14 & 61 & 30 & 20 & - & 20 & - & - \\
\hline Katavetin et al., 2010 & 13 & 14 & 1.2 & $4(31)$ & 24 & 15 & 38 & 0 & - & - & - & - & 25 \\
\hline Evliyaoglu et al., 2010 & 1 & 7 & 0.7 & $1(100)$ & 24 & 0 & 100 & 0 & 0 & 100 & 100 & 100 & 0 \\
\hline Locatelli et al., 2010 & 4 & 10.5 & - & - & - & - & - & - & - & - & - & - & - \\
\hline Zada et al., 2009 & 10 & 13 & 1.4 & $10(100)$ & 34 & 10 & 60 & 10 & 33 & 33 & 20 & 90 & 10 \\
\hline Frazier et al., 2008 & 1 & 14 & 3.0 & $1(100)$ & 8 & 0 & 0 & 0 & - & 0 & 100 & 100 & 0 \\
\hline Takanashi et al., 2005 & 4 & 2 & 0.6 & $0(0)$ & - & 0 & 0 & 100 & - & - & - & - & - \\
\hline Kim et al., 2004 & 1 & 11 & 1.6 & $1(100)$ & 4 & 100 & 0 & 0 & - & - & - & 0 & 100 \\
\hline Im et al., 2003 & 1 & 12 & 1.6 & $1(100)$ & 26 & 100 & 100 & 0 & - & - & - & 100 & 0 \\
\hline Israel et al., 2000 & 1 & 13 & 1.5 & $1(100)$ & 5 & 100 & 0 & 0 & - & 100 & 100 & 0 & 100 \\
\hline Setian et al., 1999 & 1 & 8 & 1.0 & $1(100)$ & - & 0 & 100 & 0 & - & - & - & - & - \\
\hline Christophe et al., 1993 & 7 & 4.3 & 1.4 & $2(29)$ & 24 & 0 & 14 & 43 & - & - & - & - & 0 \\
\hline Voelker et al., 1991 & 1 & 15 & - & $1(100)$ & 96 & 0 & 100 & 0 & 0 & 100 & 100 & - & 0 \\
\hline Towbin et al., 1987 & 1 & 10 & - & - & - & 0 & 100 & 0 & - & - & - & - & - \\
\hline
\end{tabular}

Hypopit $=$ hypopituitarism; impr = improved; incid = incidental; pit $=$ pituitary function; pts $=$ patients; recur $=$ recurrence .

\section{Presentation and Endocrinologic Assessment}

The 163 cases of pediatric RCCs previously reported in the literature are summarized in Table 4. Similar to our series, the median age at diagnosis was approximately 11 years, the median cyst diameter was $0.8 \mathrm{~cm}$ (range $0.6-3.0$ $\mathrm{cm}$ ), and there was a slight female predominance. Collective analysis suggests that $47 \%$ of patients present with headaches, $50 \%$ present with an underlying endocrinopathy, and $10 \%$ endorse subjective visual disturbance. ${ }^{1,3,5,6}$, 8,10-13,15-19,22,23,25,26,28 Approximately 1 in 6 RCCs are incidentally diagnosed. In the 24 patients reported on in our series, the rate of RCC-associated headache (79\%) was higher than the average rate noted in the collective analysis, but similar to the rates reported in other surgical series. ${ }^{28}$

In our study, documented visual field deficit was observed in only 1 patient and pituitary-related endocrinopathy in $3(12.5 \%)$. An additional 3 patients presented with an underlying endocrinopathy that was not deemed to be related to the RCC. Of the 6 individuals with hormonal disturbance, 4 patients were symptomatic, presenting with DI, growth delay, precocious puberty, or hypothyroidism. In each of these cases, symptom onset preceded the radiological diagnosis of RCCs. In the 2 individuals whose RCCs prompted formal endocrinological evaluation, neither patient harbored a clinically significant endocrinopathy. Of those managed conservatively, 1 individual was found to develop delayed hypopituitarism in the form of symptomatic GH deficiency. Thus, in the absence of clinical signs of hormonal excess or deficiency, the likelihood of a clinically relevant RCC-related endocrinopathy, either at diagnosis or during subsequent follow-up, appears small.

\section{Surgical Outcomes}

Seven patients in our study underwent endoscopic RCC cyst fenestration; complete cyst fenestration was achieved in all but 1 patient who subsequently developed a recurrence requiring reoperation. Headache resolution was achieved in 5 (71\%) of the 7 cases, and the 1 patient with preoperative visual field deficit had improvement of her vision following surgery. Our results are similar to those of Zada et al. ${ }^{28}$ who documented surgical outcomes in 10 pediatric patients who underwent RCC fenestration. In their series, headache resolution occurred in $88 \%$ of patients, and 2 of 6 individuals had improvement in preoperative pituitary insufficiency. However, one-third of patients in their series developed new or worsening HPA dysfunction following surgery. In our series, transient DI occurred in $3(43 \%)$ of 7 cases, and 1 patient required a brief course of hydrocortisone therapy. At last follow-up, however, no patient required ongoing hormone replacement therapy, indicating that for some, postoperative pituitary insufficiency may be temporary. There are few other series that document long-term outcomes of surgery for pediatric RCC. To date, 60 cases of surgically managed pediatric RCC have been documented in the literature (Table 4). The majority of the surgical cases in the literature have been approached via the transsphenoidal corridor, although 7 patients, described in 4 different series, have undergone a transcranial approach for RCC fenestration. ${ }^{6,10,12,28}$ Pooled analysis of all surgically managed cases suggests that preoperative endocrinopathy may improve in $25 \%$ of patients, while new or worsening anterior pituitary dysfunction may occur in $27 \%$ of cases, with a postoperative DI rate of 27\%., 3,6,10-13,15-17,22,26,28 Complete cyst fenestration was 
achieved in $82 \%$ of reported cases in the literature, with an $18 \%$ recurrence rate over a 33 -month median followup period. The recurrence rate for RCCs treated via the transsphenoidal approach was approximately 15\% (8 of 53 cases) compared with $43 \%$ (3 of 7 cases) for the RCCs approached via craniotomy.

\section{Surgical Versus Conservative Management}

Patients were considered candidates for surgery in our case series if they harbored visual field deficits, imaging evidence of chiasmal compression, or medically refractory headaches. In our series, conservatively and surgically managed patients presented at a similar age with similar cyst sizes (Table 1). Our conservatively managed patients tended to have increased rates of hypopituitarism at presentation compared with their surgically managed counterparts, although this difference was not statistically significant. Despite a small sample size in the operative cohort, both groups had similar rates of radiological cyst progression (29\% for the conservatively managed cohort and $25 \%$ for the surgically managed cohort). Nonetheless, cyst progression was not associated with development of new hormonal deficit, worsening headaches, or new visual field disturbance. Thus, in the absence of deteriorating visual acuity or evidence of chiasmal compression, cyst progression alone may not be an absolute indication for surgery.

Cyst regression occurred exclusively in the conservatively managed cohort. As only 4 patients in the surgical cohort had repeat imaging prior to cyst fenestration, this trend did not reach statistical significance $(\mathrm{p}=0.16)$. The median time to cyst regression was longer than the median time to surgical intervention (23.5 months vs 5 months). Thus, it is possible that cysts that were surgically fenestrated in this series might have decreased in size had surgery not been performed. Cysts that involuted spontaneously tended to occur in younger patients with symptomatic, larger cysts (Table 2), but yet again, with a small sample size, statistical significance was not achieved. Interestingly, cyst shrinkage was not associated with headache resolution. Cyst regression and progression have been reported previously. In an adult series of RCCs, Aho et al. ${ }^{1}$ reported a $31 \%$ rate of cyst progression after 9 years of follow-up, which is similar to our progression rate of $25 \%$. Similarly, in a cohort of adult and pediatric patients, Amhaz et al. ${ }^{2}$ described an involution rate of $31 \%$ over a similar time frame. Thus, pediatric RCCs seem to mirror the radiographic progression and involution patterns observed in adults.

\section{Recommendations}

In our surgical cohort, all patients reported severe headaches compared with $71 \%$ of individuals managed in a conservative fashion. At last follow-up, however, the incidence of headaches was similar in both groups (29\%). Although "medically refractory headaches" is a subjective surgical indication, the headache remission rate in this population following surgery was approximately $70 \%$, which is consistent with that in previous studies. ${ }^{1,28}$ Notably, the rate of spontaneous headache resolution in the conservatively managed cohort was $58 \%$. Thus, as more than half of patients may have spontaneous headache resolution, it seems reasonable to offer patients a period of watchful waiting prior to advocating surgery as a means to manage patients who present with headache.

Based on our results and our review of the literature, we suggest that RCC fenestration may be indicated in patients who develop visual field deficits, show radiological evidence of chiasmal compression, or have medically refractory headaches. For patients with newly diagnosed RCCs identified during the evaluation of headaches, we recommend over-the-counter analgesic treatment. If headaches do not respond to this therapy, patients should be referred to a pediatric headache neurologist for consideration of alternative medical strategies. We recommend annual MRI studies and clinic visits to assess for RCC progression and new symptom development. In our series, the median time to cyst progression was 72 months; therefore, radiographic stability of an RCC for up to 6 years does not rule out delayed progression. Thus, close follow-up, with serial imaging, is prudent.

In our series, evidence of pituitary-related endocrinopathy was not an absolute surgical indication. Indeed, review of the literature suggests that $25 \%$ of patients may have improvement in preoperative endocrinopathy following RCC fenestration, but that $25 \%$ of patients may develop hypopituitarism following surgery and that an additional $27 \%$ of patients may develop postoperative DI. Thus, we think that the risks and benefits of cyst fenestration for treatment of an endocrinopathy that can otherwise be managed well medically must be carefully discussed with the patient and his or her family.

\section{Limitations}

Our work, of course, has several limitations. First, this is a retrospective analysis of a rare condition in pediatric patients. Our results are therefore subject to the inherent biases of retrospective analyses and must be interpreted with this in mind. Second, we reported only 7 cases of RCCs that were treated with surgery. Thus, while our conservatively and surgically managed patient cohorts appear similar (Table 1), our study is certainly underpowered to detect subtle differences between the groups. Additionally, although our surgical criteria (visual field deficits, radiographic evidence of chiasmal compression, or medical refractory headaches) did not change over the course of the study period, it is hard to standardize the definition of "medically refractory headaches." It is possible that our proclivity to describe a headache as medically refractory may have changed over time, confounding our results further. Nevertheless, we feel that our results offer new insights that may aid in the management of pediatric RCCs.

\section{Conclusions}

Pediatric RCCs are benign sellar lesions that have not been fully characterized in the pediatric population. Headaches are a predominant feature of pediatric RCCs, and while cyst fenestration is associated with headache reduction in most patients, a significant percentage of conservatively managed pediatric patients with RCCs will have improvement in their headaches without surgery. Like their adult counterparts, pediatric RCCs may exhibit spontaneous growth and shrinkage. Thus, in the absence of optic 
compression, visual field deficit, or diagnostic uncertainty, a subset of pediatric RCCs can be managed conservatively.

\section{References}

1. Aho CJ, Liu C, Zelman V, Couldwell WT, Weiss MH: Surgical outcomes in 118 patients with Rathke cleft cysts. J Neurosurg 102:189-193, 2005

2. Amhaz HH, Chamoun RB, Waguespack SG, Shah K, McCutcheon IE: Spontaneous involution of Rathke cleft cysts: is it rare or just underreported? J Neurosurg 112:1327-1332, 2010

3. Christophe C, Flamant-Durand J, Hanquinet S, Heinrichs C, Raftopoulos C, Sariban E, et al: MRI in seven cases of Rathke's cleft cyst in infants and children. Pediatr Radiol 23:79-82, 1993

4. Culver SA, Grober Y, Ornan DA, Patrie JT, Oldfield EH, Jane JA Jr, et al: a case for conservative management: characterizing the natural history of radiographically diagnosed Rathke cleft cysts. J Clin Endocrinol Metab 100:3943-3948, 2015

5. Daubenbüchel AM, Hoffmann A, Gebhardt U, WarmuthMetz M, Sterkenburg AS, Müller HL: Hydrocephalus and hypothalamic involvement in pediatric patients with craniopharyngioma or cysts of Rathke's pouch: impact on longterm prognosis. Eur J Endocrinol 172:561-569, 2015

6. Evliyaoglu O, Evliyaoglu C, Ayva S: Rathke cleft cyst in seven-year-old girl presenting with central diabetes insipidus and review of literature. J Pediatr Endocrinol Metab 23:525-529, 2010

7. Fager CA, Carter H: Intrasellar epithelial cysts. J Neurosurg 24:77-81, 1966

8. Frazier JL, Chaichana K, Jallo GI, Quiñones-Hinojosa A: Combined endoscopic and microscopic management of pediatric pituitary region tumors through one nostril: technical note with case illustrations. Childs Nerv Syst 24:1469-1478, 2008

9. Han SJ, Rolston JD, Jahangiri A, Aghi MK: Rathke's cleft cysts: review of natural history and surgical outcomes. J Neurooncol 117:197-203, 2014

10. Hayashi Y, Kita D, Fukui I, Sasagawa Y, Oishi M, Okajima M, et al: Pediatric symptomatic Rathke cleft cyst compared with cystic craniopharyngioma. Childs Nerv Syst 32:16251632, 2016

11. Im SH, Wang KC, Kim SK, Chung YN, Kim HS, Lee CH, et al: Transsphenoidal microsurgery for pediatric craniopharyngioma: special considerations regarding indications and method. Pediatr Neurosurg 39:97-103, 2003

12. Israel ZH, Yacoub M, Gomori JM, Dotan S, Fellig Y, Shoshan Y, et al: Rathke's cleft cyst abscess. Pediatr Neurosurg 33:159-161, 2000

13. Jahangiri A, Molinaro AM, Tarapore PE, Blevins L Jr, Auguste KI, Gupta N, et al: Rathke cleft cysts in pediatric patients: presentation, surgical management, and postoperative outcomes. Neurosurg Focus 31(1):E3, 2011

14. Jane JA Jr, Thapar K, Kaptain GJ, Maartens N, Laws ER Jr: Pituitary surgery: transsphenoidal approach. Neurosurgery 51:435-444, 2002

15. Katavetin P, Cheunsuchon P, Grant E, Boepple PA, HedleyWhyte ET, Misra M, et al: Rathke's cleft cysts in children and adolescents: association with female puberty. J Pediatr Endocrinol Metab 23:1175-1180, 2010

16. Kim JE, Kim JH, Kim OL, Paek SH, Kim DG, Chi JG, et al: Surgical treatment of symptomatic Rathke cleft cysts: clinical features and results with special attention to recurrence. J Neurosurg 100:33-40, 2004

17. Lim HH, Yang SW: Risk factor for pituitary dysfunction in children and adolescents with Rathke's cleft cysts. Korean J Pediatr 53:759-765, 2010

18. Locatelli D, Massimi L, Rigante M, Custodi V, Paludetti G, Castelnuovo P, et al: Endoscopic endonasal transsphenoidal surgery for sellar tumors in children. Int J Pediatr Otorhinolaryngol 74:1298-1302, 2010

19. Oh YJ, Park HK, Yang S, Song JH, Hwang IT: Clinical and radiological findings of incidental Rathke's cleft cysts in children and adolescents. Ann Pediatr Endocrinol Metab 19:20-26, 2014

20. Park M, Lee SK, Choi J, Kim SH, Kim SH, Shin NY, et al: Differentiation between cystic pituitary adenomas and Rathke cleft cysts: a diagnostic model using MRI. AJNR Am J Neuroradiol 36:1866-1873, 2015

21. Ross DA, Norman D, Wilson CB: Radiologic characteristics and results of surgical management of Rathke's cysts in 43 patients. Neurosurgery 30:173-179, 1992

22. Setian N, Aguiar CH, Galvão JA, Crivellaro CE, Dichtchekenian V, Damiani D: Rathke's cleft cyst as a cause of growth hormone deficiency and micropenis. Childs Nerv Syst 15:271-273, 1999

23. Takanashi J, Tada H, Barkovich AJ, Saeki N, Kohno Y: Pituitary cysts in childhood evaluated by MR imaging. AJNR Am J Neuroradiol 26:2144-2147, 2005

24. Teramoto A, Hirakawa K, Sanno N, Osamura Y: Incidental pituitary lesions in 1,000 unselected autopsy specimens. Radiology 193:161-164, 1994

25. Towbin RB, Ball WS, Kaufman RA: Pediatric case of the day. Rathke's cleft cyst. Radiographics 7:385-388, 1987

26. Voelker JL, Campbell RL, Muller J: Clinical, radiographic, and pathological features of symptomatic Rathke's cleft cysts. J Neurosurg 74:535-544, 1991

27. Yoshida J, Kobayashi T, Kageyama N, Kanzaki M: Symptomatic Rathke's cleft cyst. Morphological study with light and electron microscopy and tissue culture. J Neurosurg 47:451-458, 1977

28. Zada G, Ditty B, McNatt SA, McComb JG, Krieger MD: Surgical treatment of Rathke cleft cysts in children. Neurosurgery 64:1132-1138, 2009

\section{Disclosures}

The authors report no conflict of interest concerning the materials or methods used in this study or the findings specified in this paper.

\section{Author Contributions}

Conception and design: Jane, Shepard, Elzoghby, Payne. Acquisition of data: Jane, Shepard, Elzoghby. Analysis and interpretation of data: all authors. Drafting the article: all authors. Critically revising the article: all authors. Reviewed submitted version of manuscript: all authors. Approved the final version of the manuscript on behalf of all authors: Jane. Statistical analysis: Shepard. Administrative/technical/material support: Jane, Payne. Study supervision: Jane.

\section{Supplemental Information \\ Previous Presentations}

Portions of this work were presented as proceedings at the 38th Annual Meeting of the AANS/CNS Section on Pediatric Neurological Surgery, Boston, MA, December 1-4, 2009, and the 27th Annual Meeting of the North American Skull Base Society, New Orleans, LA, March 3-5, 2017.

\section{Current Affliations}

Dr. Kiehna: Department of Neurological Surgery, Novant Health Brain and Spine Surgery, Charlotte, NC.

\section{Correspondence}

John A. Jane Jr., Department of Neurosurgery, University of Virginia Health System, PO Box 800212, Charlottesville, VA 229080711. email: johnjanejr@virginia.edu. 